\title{
The effect of starch isolation method on physical and functional properties of Portuguese nut starches. II. Q. rotundifolia Lam. and Q. suber Lam. acorns starches
}

\author{
Paula Reis Correia ${ }^{\mathrm{a}, *}$, Maria Cristiana Nunes ${ }^{\mathrm{b}, \mathrm{c}}$, Maria Luísa Beirão-da-Costa ${ }^{\mathrm{c}}$

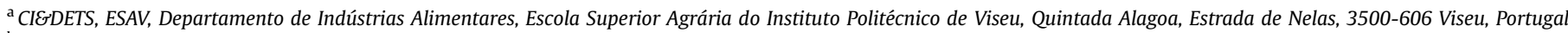 \\ ${ }^{\mathrm{b}}$ Núcleo de Investigação em Engenharia Alimentar e Biotecnologia, Instituto Piaget-ISEIT de Almada, Quinta da Arreinela de Cima, 2800-305 Almada, Portugal \\ ${ }^{\mathrm{c}}$ CEER - Biosystems Engineering, Institute of Agronomy, Technical University of Lisbon, Tapada da Ajuda, 1349-017 Lisboa, Portugal
}

\section{A R T I C L E I N F O}

\section{Article history:}

Received 26 July 2011

Accepted 26 June 2012

\section{Keywords:}

Acorns

Isolation method

Starch

Functional properties

Thermal properties

Rheological properties

\begin{abstract}
A B S T R A C T
A new starch was isolated from fruits of two acorn species, Quercus rotundifolia and Quercus suber by alkaline (A3S) and enzymatic (ENZ) methods and physical and functional properties were studied. The isolation method induced changes in most of those properties in the isolated starches, mainly in resistant starch content, syneresis, pasting, thermal and rheological properties. Isolated acorn starches presented high amylose content (53-59\%) and resistant starch content (30.8-41.4\%). Acorn starches showed limited and similar solubility values and swelling power values, showing a gradual increase from $60^{\circ} \mathrm{C}$ to $90{ }^{\circ} \mathrm{C}$. The pasting temperatures ranged from 67.5 to $72.0{ }^{\circ} \mathrm{C}$ and pastes did not present breakdown, which is suggestive of a high paste stability of acorn starches during heating. At ambient temperature the turbidity and syneresis values were low, but when held at freezing temperatures the syneresis significantly increased. Thermal analysis revealed that the acorn starches easily undergo transition phenomena as shown by the low $T_{0}$ and enthalpy values $(4.1-4.3 \mathrm{~J} / \mathrm{g})$, these effects were more evident in starches isolated by ENZ method. Pastes are more elastic than viscous and form strong gels after cooling. Q. suber starch was shown to be more sensitive to the effect of isolation method. Generally, starch isolated by enzymatic method presented less interesting functional properties, since this isolation procedure greater affected the raw structure of starches.
\end{abstract}

(c) 2012 Elsevier Ltd. All rights reserved.

\section{Introduction}

Acorn fruits from Quercus suber (QS) and Quercus rotundifolia $(\mathrm{QR})$ are important forestry resources in the Centre and South Portugal regions. Traditionally, these fruits are mainly used for the feeding of Iberic pigs. In past times of scarcity, the flours produced from these fruits were also used in bread production (Ribeiro, 1992), and traditional recipes still remain from these times. Other European Mediterranean countries are also consumers of these fruits as referred to Rakic, Povrenovic, Tesevic, Simic, and Maletic (2006). Keeping in mind the high starch content of these fruits (48.0\% and 49.0\% respectively for QR and QS) (Correia, Leitão, \& Beirão-da-Costa, 2009), the exploitation of these resources could be profitable. Furthermore, there has been an increased interest in new sources of starches for a wide variety of industrial applications. In this view, acorns could be a promising source of native starches for the food industry, not requiring chemical or genetic

\footnotetext{
* Corresponding author. Tel.: +351927863475.

E-mail address: paularcorreia@hotmail.com (P.R. Correia).
}

modifications. Anyhow, the knowledge of starch properties is imperative, to define its potential applications both in food and non-food industries.

Most starch isolation methods affect starch properties, which justify identification of the most suitable isolation method. In a previous work, Correia and Beirão-da-Costa (2010) reported the effects of isolation methods on QR and QS starches. The best results considering the yield, purity and pasting properties were obtained for two methods that applied low shear with alkali treatment and low shear with protease digestion. Furthermore, these methods were optimised for acorn starch isolation parameters (Correia \& Beirão-da-Costa, 2012). These methods, designated as A3S and ENZ, lead to extraction yields of $88.5 \%$ and $86.9 \%$ with a purity of $98.1 \%$ and $97.6 \%$, for QS variety.

In the literature, acorn starch properties from other oak trees, but not Quercus species were studied (Aee, Hie, \& Nishinari, 1998; Soni, Sharma, Dun, \& Gharia, 1993; Stevenson, Jane, \& Inglett, 2006). Since acorns are good sources of starch, these fruits show a large potential for commercial use.

The objectives of the present study were to evaluate the effect of starch isolation method on functional, thermal and viscoelastic 
properties of gels of acorn starches, aiming to find potential industrial applications for these underexploited raw materials.

\section{Materials and methods}

\subsection{Materials}

Q. suber Lam. and Q. rotundifolia Lam. acorns were collected in "montados" (specific designation for orchards of $Q$. suber and Q. rotundifolia) located in Idanha-a-Nova (Centre East of Portugal). Three sets of $1 \mathrm{~kg}$ of each acorn fruit were randomly harvested at maturity stage, stored, dried and milled as previously reported by Correia et al. (2009). The granule size and microphotographs of these acorn flours are reported previously (Correia et al., 2009).

\subsection{Starch extraction methods}

Starch was isolated from acorn flours using the following two methods (Correia \& Beirão-da-Costa, 2012):

\section{(1) - Alkaline $\mathrm{pH}$ using successively three sieves (A3S)}

The flours ( $120 \mathrm{~g}$ ) were soaked in $240 \mathrm{ml}$ of $0.25 \% \mathrm{NaOH}$ at $5{ }^{\circ} \mathrm{C}$ for $24 \mathrm{~h}$. Suspensions were homogenised and screened through a $180 \mu \mathrm{m}$ sieve. The procedure was repeated twice. The combined underflow was screened successively on 75 and $53 \mu \mathrm{m}$ sieves. The underflow containing the crude starch suspension was recovered in the filtrate, which was centrifuged in a Universal 16 centrifuge (Hettich Zentrifugen Company, Germany) at $800 \times g$ for $15 \mathrm{~min}$. The mucilaginous layer was scraped off and the starch sediment was suspended in water. This centrifugation step was repeated twice. Isolated starches were dried for two days at $40^{\circ} \mathrm{C}$ in a FD 115 Binder ventilated drying chamber (with an air flow of $300 \mathrm{~m}^{3} /$ hour).

\section{(2) - Enzymatic method (ENZ)}

Flour $(120 \mathrm{~g})$ and water $(360 \mathrm{ml})$ were mixed, the slurry adjusted to $\mathrm{pH} 7.5$ (with $0.1 \mathrm{M} \mathrm{NaOH}$ or $0.1 \mathrm{M} \mathrm{HCl}$ ) and protease was added (900 units). The mixture was incubated at $37^{\circ} \mathrm{C}$ for a period of $2 \mathrm{~h}$ and it was shaken at $20 \mathrm{rpm}$, in an incubation chamber EB TH15 with a shaker incubator KS-15 (Edmund Bühler GmbH, Germany). The slurry was then centrifuged under the same conditions as previously mentioned. The starch fraction was suspended, washed with water $(200 \mathrm{ml})$ and filtered through a $53 \mu \mathrm{m}$ sieve. The filtrate was centrifuged, supernatant and tailings were discarded and the starch was dried as described above.

\subsection{Amylose and resistant starch content}

The colorimetric method proposed by Juliano (1971), was used to determine amylose content, being amylose content expressed on starch basis. One hundred milligrams of each sample was weighed into a $50 \mathrm{ml}$ Erlenmeyer flask and $1 \mathrm{ml}$ of $95 \%$ ethanol and $9 \mathrm{ml}$ of $1 \mathrm{~N} \mathrm{NaOH}$ added. The mixture was heated for $10 \mathrm{~min}$ in a boiling water bath to gelatinise the starch, cooled, and transferred, with several water washings, into a $100 \mathrm{ml}$ volumetric flask. The volume was brought up with water and then well mixed. Five millilitres of starch solution was pipetted into a $100 \mathrm{ml}$ volumetric flask and $1 \mathrm{ml}$ of $1 \mathrm{~N}$ acetic acid and $2 \mathrm{ml}$ of iodine solution ( $0.2 \mathrm{~g}$ iodine and $2.0 \mathrm{~g}$ potassium iodine in $100 \mathrm{ml}$ of aqueous solution) added. The solution was made up to volume with distilled water, shaken, and allowed to stand for $20 \mathrm{~min}$. Absorbance of the solution at $620 \mathrm{~nm}$ was measured with a Lambda 25 UV/VIS spectrophotometer (PerkinElmer, Massachusetts, USA). Amylose content was determined by reference to a potato amylose (Sigma Chemical Co.) standard curve. This method was applied with an unmodified regular corn starch purchased from Sigma Chemical Co. (Ref.a S4126) used as a standard. The amylose content of the corn starch was $28 \pm 0.6 \%$, near the standard value (approximately $27 \%$ ).

Resistant starch (RS) content was determined by the method proposed by Mun and Shin (2006). RS content is a measure of indigestible starch and so an important parameter from a nutritional perspective.

All reported values are expressed on a dry weight basis (dwb) and all reagents used were of analytical grade.

\subsection{Swelling power and solubility}

The swelling power (SP) and solubility (S) were measured according to Lan, Zhihua, Yun, Bijun, and Zhida (2008). A starch suspension in water $(2 \%, \mathrm{w} / \mathrm{v})$ was incubated in a water bath for $30 \mathrm{~min}$ at different temperatures ranging from 50 to $90{ }^{\circ} \mathrm{C}$. Suspensions were centrifuged at $980 \times \mathrm{g}$ for $15 \mathrm{~min}$ in a Universal 16 centrifuge (Hettich Zentrifugen Company, Germany), the supernatant was removed and the sediment weighed. Aliquots of supernatant were dried in an oven at $105{ }^{\circ} \mathrm{C}$ till constant weight. The SP (g/g on dry weight basis) and S (\%) were calculated by Equations (1) and (2) as follows:

$$
\begin{aligned}
& \mathrm{SP}=(\mathrm{Sw} \times 100) /\left[\operatorname{Starch}_{\mathrm{dwb}} \times(100 \%-\% \mathrm{DS})\right] \\
& \mathrm{S}=\left(\mathrm{DS} / \mathrm{Starch}_{\mathrm{dwb}}\right) \times 100 \%
\end{aligned}
$$

where $\mathrm{Sw}$ is the sediment weight, Starch $\mathrm{dwb}_{\mathrm{b}}$ is the dry water basis starch weight, and DS is the total mass of dried supernatant

\subsection{Turbidity}

The turbidity of suspensions of the starch samples was measured as described by Lan et al. (2008). Starch suspensions, prepared as described in 2.4., were heated in a boiling water bath for $1 \mathrm{~h}$ with constant stirring, and cooled for $1 \mathrm{~h}$ at $30^{\circ} \mathrm{C}$. Turbidity was determined by measuring the absorbance at $620 \mathrm{~nm}$ with a CADAS 100 UV spectrophotometer (Dr Lange, Basingstoke, UK) against distilled water blank. Turbidity was expressed as transmittance percentage.

\subsection{Syneresis: stability to freezing and refrigeration}

The storage stability of the gelatinised starch suspensions at different temperatures was evaluated by syneresis degree as proposed by Rondán-Sanabria and Finardi-Filho (2009). A starch suspension of $6 \%$ solids was heated up to $95^{\circ} \mathrm{C}$ for $15 \mathrm{~min}$, cooled to $50^{\circ} \mathrm{C}$ and suspensions held at this temperature for $15 \mathrm{~min}$. Aliquots of $50 \mathrm{ml}$ were placed in centrifuge tubes and they were conditioned at three temperatures: $-18{ }^{\circ} \mathrm{C}$ (vertical freezer Siemens A+ NO FROST 1.85 - GS 32NA92, Germany), $4{ }^{\circ} \mathrm{C}$ (refrigerator Siemens KI24RA50FF Germany), and ambient temperature for 5 days. Every $24 \mathrm{~h}$, the samples were centrifuged at $8000 \times \mathrm{g}$ for $10 \mathrm{~min}$. Syneresis was measured as percentage amount of water released after centrifugation.

\subsection{Pasting properties}

The gelatinisation process was monitored in a Brabender viscoamylograph (Duisburg, Germany) viscoamylograph at $10 \%$ starch concentration, heated from $30^{\circ} \mathrm{C}$ to $95^{\circ} \mathrm{C}$, held at $95{ }^{\circ} \mathrm{C}$ for $15 \mathrm{~min}$ and then cooled until $50{ }^{\circ} \mathrm{C}$. The heating and cooling rates were $1.5^{\circ} \mathrm{C} /$ minute. Breakdown (BD), the measure of degradation of 
physical structure, was calculated by Equation (3), and setback (SB) was determined by Equation (4), both in Brabender units (BU):

$\mathrm{BD}=$ peak consistency $(\mathrm{BU})-$ minimum consistency $(\mathrm{BU})$

$\mathrm{SB}=$ consistency at $50^{\circ} \mathrm{C}(\mathrm{BU})-$ minimum consistency $(\mathrm{BU})$

\subsection{Thermal analysis}

Thermal characteristics were tested by Differential Scanning Calorimetry (DSC) on a Shimadzu calorimeter (model TA-50WSI, Japan). The instrument was calibrated using indium and deionised distilled water as standards. The samples $(7.5 \mathrm{mg})$ were weighed directly in DSC aluminium pans. Water was added to the starch samples at a ratio of $2: 1$, and then heated from $25{ }^{\circ} \mathrm{C}$ to $100{ }^{\circ} \mathrm{C}$ at $5{ }^{\circ} \mathrm{C} /$ minutes, at $30 \mathrm{ml} /$ minute as the flow rate, using nitrogen as carrier gas. Onset temperature $\left(T_{0}\right)$, peak temperature $\left(T_{p}\right)$, end set temperature $\left(T_{e}\right)$ and gelatinisation enthalpy $\Delta \mathrm{H}(\mathrm{J} / \mathrm{g}$ of dry starch) were determined. As the endotherms are essentially symmetrical, the total gelatinisation temperature range $\left(T_{r}\right)$ and peak height index (PHI) can be established by Equations (5) and Equation (6) (Krueger, Knutson, Inglett, \& Walker, 1987):

$T_{r}=\left[2\left(T_{p}-T_{o}\right)\right]$

$\mathrm{PHI}=\Delta H /\left(T_{p}-T_{o}\right)$

The transition kinetics were studied by DSC, using the heat evolution method of Borchardt and Daniels as reported by Danielenko et al. (1985). The method assumes that the reaction follows the relationship (Equation (7)).

$\mathrm{d} \alpha / \mathrm{d} t=k(1-\alpha)^{n}$

where $\mathrm{d} \alpha / \mathrm{d} t$ is the reaction rate; $k$ is the rate constant $\left(\mathrm{s}^{-1}\right) ; \alpha$ is the fractional conversion; $n$ is the reaction order. The reaction rate $\mathrm{d} \alpha /$ $\mathrm{d} t$ is obtained by dividing the peak height at a temperature $T$ by the total area. The method also assumes that the dependence of the reaction rate follows the Arrhenius expression (Equation (8)):

$\nu=\nu_{0} \mathrm{e}^{-E_{a} / \mathrm{R} T}$

where $v$ is $\mathrm{d} \alpha / \mathrm{d} t ; v_{0}$ is the constant rate; $E_{a}$ is the activation energy ( $\left.\mathrm{J} \mathrm{mol}^{-1}\right)$; $\mathrm{R}$ is the gas constant; and $T$ is the absolute temperature.

\subsection{Dynamic rheometry}

The dynamic rheological properties were monitored in-situ in a controlled stress rheometer (RS-75, Haake, Germany) coupled to a circulating water bath (DC 10, Haake, Germany), through dynamic small amplitude oscillatory shear measurements (SAOS). SAOS measurements allow the continuous assessment of dynamic moduli during temperature, time and frequency sweep testing of starch suspensions/gels. Rheological evaluation was performed according to Singh, Nakaura, Inouchi, and Nishinari (2008), using a serrated parallel plate of $35 \mathrm{~mm}$ diameter with a gap size of $1 \mathrm{~mm}$. The storage modulus $\left(G^{\prime}\right)$, loss modulus $\left(G^{\prime \prime}\right)$, and loss factor $(\tan \delta$ ) of starch suspensions of $10 \%(\mathrm{w} / \mathrm{w})$ were determined. The maximum temperature for $G^{\prime}$ was designated as $T_{G_{\max }^{\prime}}$. Breakdown in $G^{\prime}$ is the difference between peak $G^{\prime}$ and minimum $G^{\prime}$ at $90{ }^{\circ} \mathrm{C}$ holding time (Singh et al., 2008). Starch suspensions were stirred for $5 \mathrm{~h}$ with a magnetic stirrer at ambient temperature, then loaded onto the rheometer measuring device and covered with paraffin oil to minimise evaporation losses. The samples were heated from $50{ }^{\circ} \mathrm{C}$ to $90^{\circ} \mathrm{C}$ at a rate of $1.25^{\circ} \mathrm{C} /$ minute $(\omega=6.28 \mathrm{rad} / \mathrm{s})$ and held at $90{ }^{\circ} \mathrm{C}$ for $15 \mathrm{~min}$. To study the effect of storage, samples were then cooled at a rate of $0.5{ }^{\circ} \mathrm{C} /$ minute $(\omega=6.28 \mathrm{rad} / \mathrm{s})$ until a temperature of $10{ }^{\circ} \mathrm{C}$ was reached. Subsequently, time sweep tests were conducted at $10{ }^{\circ} \mathrm{C}$ during $2 \mathrm{~h}(\omega=6.28 \mathrm{rad} / \mathrm{s})$ followed by frequency sweep tests $(\omega=0.01-111.7 \mathrm{rad} / \mathrm{s})$. All tests were conducted at a $2 \mathrm{~Pa}$ constant shear stress value inside the linear viscoelastic regime. Only the variations that did not exceed 5\% between triplicate runs were considered.

\subsection{Statistical analysis}

All of the data represents averages of at least three different determinations. Results were analysed using the SPSS ${ }^{\circledR}$ for Windows version 17.0 and Statistic ${ }^{\circledR}$ version 6 software. The data was subjected to one-way analysis of variance (ANOVA) test. The separation of means or significant difference comparisons of all parameters were tested by Tukey's HSD test. Pearson correlation coefficients $(r)$ for the relationships between properties were also calculated. The level of significance used for all of the statistical tests was $95 \%$.

\section{Results and discussion}

\subsection{Swelling power and solubility}

Swelling power and solubility values, as shown in Fig. 1, are similar for both acorn starches and isolation methods, increasing gradually from $60^{\circ} \mathrm{C}$ to $90^{\circ} \mathrm{C}$, meaning that besides a similarity of behaviour among the two species, the isolation procedure does not seem to affect these properties. This pattern is characterised by a positive correlation between SP and solubility $(r=0.96, p \leq 0.01)$ suggesting that solubilisation occurred along with granular swelling.

SP values are low when compared to other starch sources such as potato starch (56.2-64.7 g/g) (Kaur, Singh, \& Singh, 2006), but
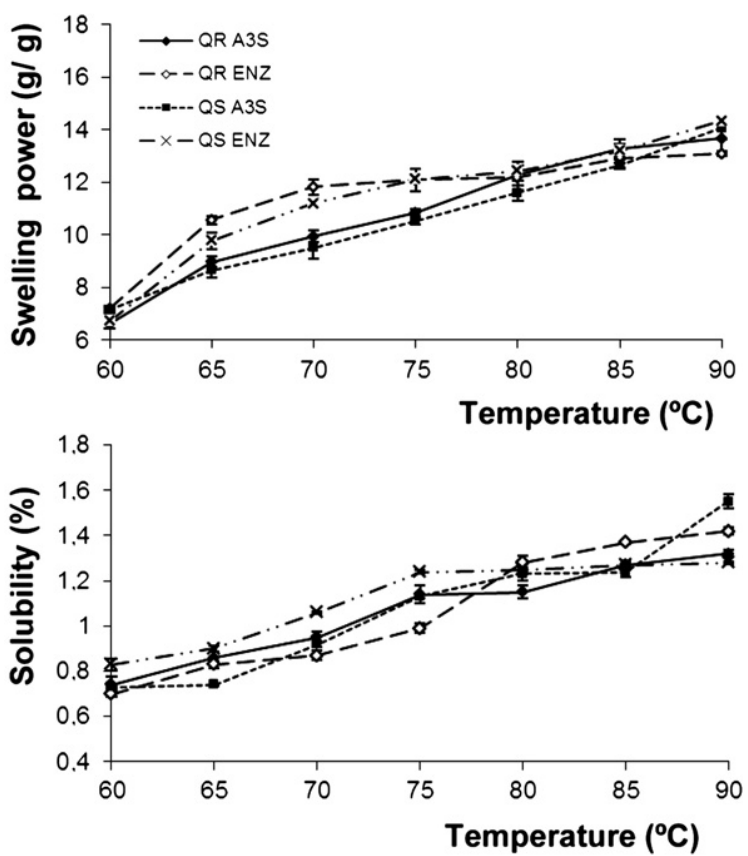

Fig. 1. Swelling power and solubility of acorn starches. QR: Quercus rotundifolia; QS: Quercus suber; A3S: alkali starch isolation method; ENZ: enzymatic isolation method. 
Table 1

Amylose and resistant starch (RS) contents of acorn starches.

\begin{tabular}{llll}
\hline & & Amylose & RS \\
\hline Q. rotundifolia & A3S & $53.7 \pm 0.3 \mathrm{a}$ & $41.4 \pm 1.0 \mathrm{c}$ \\
& ENZ & $54.5 \pm 0.4 \mathrm{a}$ & $37.9 \pm 0.4 \mathrm{~b}$ \\
Q. suber & A3S & $57.9 \pm 1.0 \mathrm{~b}$ & $39.2 \pm 0.8 \mathrm{bc}$ \\
& ENZ & $59.4 \pm 0.7 \mathrm{~b}$ & $30.8 \pm 0.7 \mathrm{a}$ \\
\hline
\end{tabular}

Values are expressed as mean \pm standard error of mean. Means sharing the same letters in columns are not significantly different from each other (Tukey's HSD test, $p<0.05)$.

A3S: alkali starch isolation method; ENZ: enzymatic isolation method.

similar to giginya palm seeds (about $15 \mathrm{~g} / \mathrm{g}$ ) (Barminas et al., 2008) and to chestnut starches (13.6-17.3 g/g) (Correia, Nunes, \& Beirãoda-Costa, 2012). The lower values for SP could be influenced by the high amylose content (Rondán-Sanabria \& Finardi-Filho, 2009) of these two acorn starches (Table 1). The amylose content for all of the samples was always high, ranging from $53.4 \%$ to $59.4 \%$, no significant differences were found between the two different isolation methods for the same sample. Stevenson, Jane, and Inglett (2006) found also high amylose content for Quercus palustris Muench, 43.4\%. Similar high amylose content was reported for some pulse starches (Hoover, Hughes, Chung, \& Liu, 2010), and also for chestnut starches (Correia, Nunes, \& Beirão-da-Costa, 2012), also exhibiting low SP values.

The explanation for the limited swelling values obtained over the temperature range could be also attributed to the presence of strong bonding forces in the starch granules (Soni et al., 1993), or influence either by high levels of cross-linking (Mirmoghtadaie, Kadivar, \& Shahedi, 2009). Furthermore, Adebowale, Afolabi, and Olu-Owolabi (2006) attributed to C-type starches typical of legumes limited swelling. These two latter explanations seem to fit with acorn starches, since they also present a C-type X-ray pattern and degrees of crystallinity between $43.1 \%$ and $46.6 \%$ (unpublished data).

\subsection{Pasting properties, turbidity and syneresis}

Pasting properties and turbidity of acorn starches are presented in Table 2. Acorn starches presented high pasting temperature (PT), similar to pin oak starch $\left(71.5^{\circ} \mathrm{C}\right)$ (Stevenson et al., 2006) the effect of the isolation method was not evident. Furthermore, the higher pasting temperature implies a higher cooking time for this starch. The results of pasting temperature are in conformity with the encountered results for swelling powers of the starches. Generally, high pasting temperatures indicate high resistance to swelling.

Table 2

Pasting properties and turbidity of acorn starches.

\begin{tabular}{lccccc}
\hline \multirow{2}{*}{$\begin{array}{l}\text { Functional } \\
\text { property }\end{array}$} & \multicolumn{2}{l}{ Q. rotundifolia } & & \multicolumn{2}{l}{ Q. suber } \\
\cline { 2 - 3 } \cline { 5 - 6 } & A3S & ENZ & A3S & ENZ \\
\hline PT $\left({ }^{\circ} \mathrm{C}\right)$ & $70.5 \pm 0.9 \mathrm{ab}$ & $67.5 \pm 0.7 \mathrm{~b}$ & $72.0 \pm 0.6 \mathrm{a}$ & $70.3 \pm 1.0 \mathrm{ab}$ \\
$\mathrm{C} 55^{\circ} \mathrm{C}(\mathrm{BU})$ & $1506 \pm 29 \mathrm{c}$ & $1265 \pm 35 \mathrm{ab}$ & & $1280 \pm 35 \mathrm{ab}$ & $1173 \pm 41 \mathrm{a}$ \\
$\mathrm{CAH}(\mathrm{BU})$ & $1407 \pm 47 \mathrm{a}$ & $1290 \pm 38 \mathrm{ab}$ & & $1243 \pm 26 \mathrm{bc}$ & $1120 \pm 12 \mathrm{c}$ \\
$\mathrm{FC}(\mathrm{BU})$ & $2575 \pm 31 \mathrm{~b}$ & $2453 \pm 35 \mathrm{a}$ & & $2540 \pm 23 \mathrm{~b}$ & $2750 \pm 32 \mathrm{c}$ \\
$\mathrm{SB}(\mathrm{BU})$ & $1180 \pm 41 \mathrm{c}$ & $1155 \pm 32 \mathrm{c}$ & & $1300 \pm 29 \mathrm{~b}$ & $1630 \pm 2 \mathrm{a}$ \\
$\mathrm{TM}\left(\% T_{620}\right)$ & $2.43 \pm 0.2 \mathrm{a}$ & $2.40 \pm 0.03 \mathrm{a}$ & $2.37 \pm 0.02 \mathrm{a}$ & $2.35 \pm 0.02 \mathrm{a}$ \\
\hline
\end{tabular}

Values are expressed as mean \pm standard error of mean. Means sharing the same letters in rows are not significantly different from each other (Tukey's HSD test, $p<0.05)$.

Consistency is reported as BU (Brabender units).

PT, pasting temperature; $\mathrm{C} 95{ }^{\circ} \mathrm{C}$, consistency at $95{ }^{\circ} \mathrm{C}$; $\mathrm{CAH}$, consistency after holding at $95{ }^{\circ} \mathrm{C}$; FC, final consistency; SB, setback [SB = consistency at $50{ }^{\circ} \mathrm{C}$ (BU) - minimum consistency (BU)]; TM, transmittance; A3S, alkaline starch isolation method; ENZ, enzymatic isolation method.
The studied acorn starches, as well as what was already found for chestnut starches (Correia et al., 2012), do not present a proper peak viscosity, and so, showing a similar profile to a cross-linked starch suspension (Thomas \& Atwell, 1999). Furthermore, the absence of breakdown (BD) means that hot pastes from acorn starches presented high stability (Lan et al., 2008), and a high resistance to mechanical stirring under hot conditions. This cooked paste stability may show the potential of the starch for use in porridge (Hadimani \& Malleshi, 1993). Stevenson et al. (2006) also found similar behaviour for other acorn starch pastes ( $Q$. palustris Muench.).

The consistency at $95^{\circ} \mathrm{C}$ after $15 \mathrm{~min}$ of holding reflected the hot paste consistency. Table 2 shows that this consistency was affected by starch isolation methods. For both species the A3S starch isolation method showed the highest values.

Cold paste consistency increased upon cooling, due to the aggregation of the amylose molecules. This characteristic is estimated by the final consistency (FC). In our study, acorn starches presented high and similar FC. Other authors also reported, as the most distinctive acorn starch pastes properties, the high final consistency and setback (Stevenson et al., 2006).

SB consistency is defined as the degree of re-association between the starch molecules involving amylose (Charles, 2004), that have leached from swollen starch granules during cooling, and it is generally used as a measure of the gelling ability or retrogradation tendency of starch (Singh, Bawa, Singh, \& Saxena, 2009). A high setback consistency is associated with cohesiveness of the pastes (Otebayo, Aina, Asiedu, \& Bokanga, 2006), meaning, in a practical sense, the paste's ability to maintain a coherent structure, and this seems to be the case in acorn starches. The SB, evaluated by the difference in consistencies of the pastes at the end and at $95{ }^{\circ} \mathrm{C}$, was clearly affected by the isolation method in QS starches, presenting low values for A3S method. This could be attributed to a lower degree of amylose leaching, as suggested by the low values of solubility of acorn starches, or a low proportion of long amylopectin chains (Naguleswaran, Vasathan, Hoover, \& Liu, 2010). As the solubility values of all starches are very low and the differences between them are marginal, it is possible to conclude that the starch structure will be a major factor in starch pasting properties. Furthermore, acorn starches presented paste properties similar to cross-linked starches and for this type of starches a reduction of amylose leaching, granular swelling and degree of SB has been attributed (Hoover et al., 2010). A positive correlation between the amylose content and SB, $r=0.905(p<0.01)$, and a negative one between amylose and resistant starch, $r=-0.862$ $(p<0.01)$ was noticed. It must be emphasised that the high consistency immediately acquired when the pastes were cooled, suggests possible new applications of this starch as an alternative to more conventional products.

The RS values are presented in Table 1 . Acorns presented a high content of RS, QS starches presenting the lower value, 30.8\% for ENZ starch isolation method. Thus, acorn starch could be classified as type II since it is a raw granular starch (Liu, 2005). The encountered values are higher then the RS content of high-amylose pea starches (18.0-19.6\%) (Themeier, Hollmann, Neese, \& Linndhauer, 2005), but lower than those of chestnuts (Correia et al., 2012), high-amylose maize starch (49.1\% and 54.4\%) (Themeier et al., 2005), and potato native starch (78.8\%) (McCleary et al., 2006), Acorn starches presented similar RS values to Palmyra starch (32.2\%) (Naguleswaran et al., 2010).

Acorn starches presented high transmittance values, and the isolation method did not affect this property. Singh, Nakaura, Inouchi, \& Nishinari (2007) reported that starch granules disintegrate less in the presence of higher amylose content, and that seems to be the case in acorn starches. The high transmittance 
values of the acorn starches can be explained by their limited swelling power and low solubility. In this respect these starches resemble cross-linked starch, in which the identity of its granules is retained after heating (Kaur, Singh, \& Sodhi, 2002).

Starch gels as a metastable and non-equilibrium systems undergo structural changes during storage (Ferrero, Martin, \& Zaritzky, 1994) always leading to some degree of syneresis. This effect is also an index of the degree of starch retrogradation (Wang et al., 2010). Syneresis characterises the starch stability to different storage conditions (Fig. 2). At ambient temperature and refrigeration temperature the pastes presented a high stability, meaning that they could form an elastic gel with high water holding capacity. Only when the starch gels were subjected to freezing temperatures a certain amount of water was released. As it is well known, the paste retrogradation is indirectly influenced by the structural
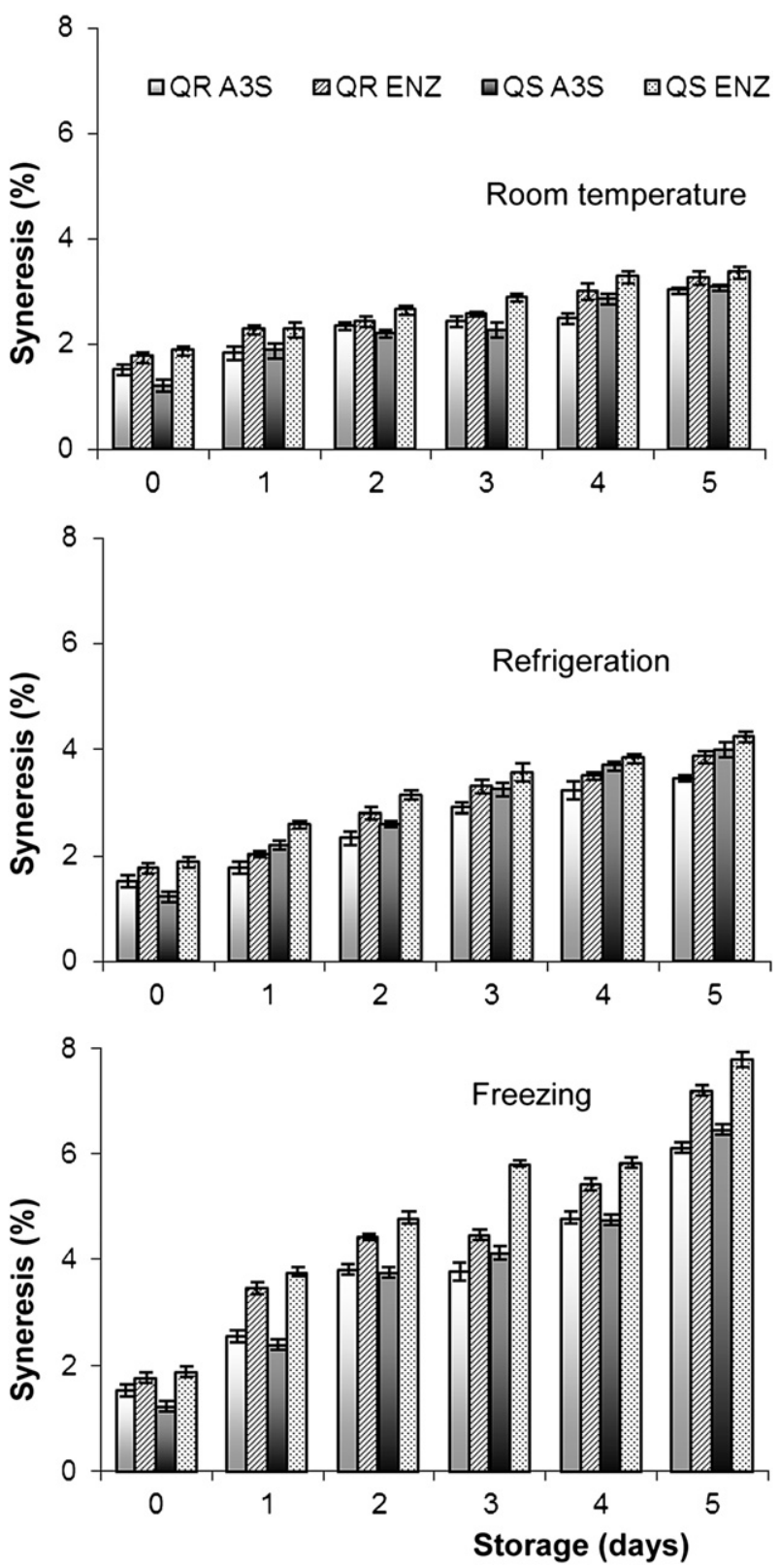

Fig. 2. Syneresis of acorn starch pastes after storage at ambient, refrigeration and freezing temperatures. QR: Q. rotundifolia; QS: Q. suber; A3S: alkaline isolation method; ENZ: enzymatic isolation method. arrangement of the starch chains within the amorphous and crystalline regions of the non-gelatinised granule, acting in the granule breakdown during gelatinisation and also in the interactions occurring within the starch chains during the gel storage (Perera \& Hoover, 1999). This phenomenon is responsible for undesired behaviours, like bread ageing. The results showed that this phenomenon occurs only in limited extension for acorns gels.

\subsection{Thermal properties}

The typical DSC (Differential Scanning Calorimetry) traces of gelatinisation for acorn starches are represented in Fig. 3. The results of thermal analysis are shown in Table 3. Although the results showed some significant differences in transition temperatures, $T_{0}$ (onset temperature) and $T_{p}$ (peak temperature), in practice the encountered differences range $1-2{ }^{\circ} \mathrm{C}$, which from an utilisation point of view are not important. A difference was observed between DSC gelatinisation onset and the pasting temperature measured by the Brabender viscoamylograph, suggesting that the melting process preceded the initial increase in viscosity (Chaisawang \& Suphantharika, 2006). $T_{0}$ of both species occur close to $58-60{ }^{\circ} \mathrm{C}$, lower than other acorn starches $65^{\circ} \mathrm{C}$ and $80-85^{\circ} \mathrm{C}$, respectively found for Q. palustris and Q. leucothichophora (Soni et al., 1993; Stevenson et al., 2006).

Both gelatinisation temperature and enthalpy of starches are known to depend on micro-structures, presence of crystalline regions of different degrees of organisation in the granule, granule size, and amylose-to-amylopectin ratio (Ahmad, Williams, Doublier, Durand, \& Buléon, 1999; Singh \& Singh, 2001). Moreover, DSC gelatinisation temperature is indicative of the degree of order (crystallite perfectness), whilst enthalpy is a measure of the extent of order (amount of crystallinity).

Generally, acorns starches presented low enthalpy values $(4.1-4.3 \mathrm{~J} / \mathrm{g})$ and $E_{a}\left(1874-2189 \mathrm{~J} \mathrm{~mol}^{-1}\right)$, and the isolation method did not significantly affect this characteristic. When compared with chestnut starches (Correia et al., 2012), acorn starches generally presented high values of enthalpy and activation energy, meaning that acorn starches need more energy to achieve gelatinisation, reflecting a strong and better organised structure of molecules in starch granules. The enthalpy $(\Delta \mathrm{H})$ values are similar to highamylose starches, like pea wrinkled starch and other pulsed starches (Hoover et al., 2010), to potato (4.35 J/g) and cassava (5.01 J/g) (Barminas et al., 2008), but lower relatively to Q. palustris

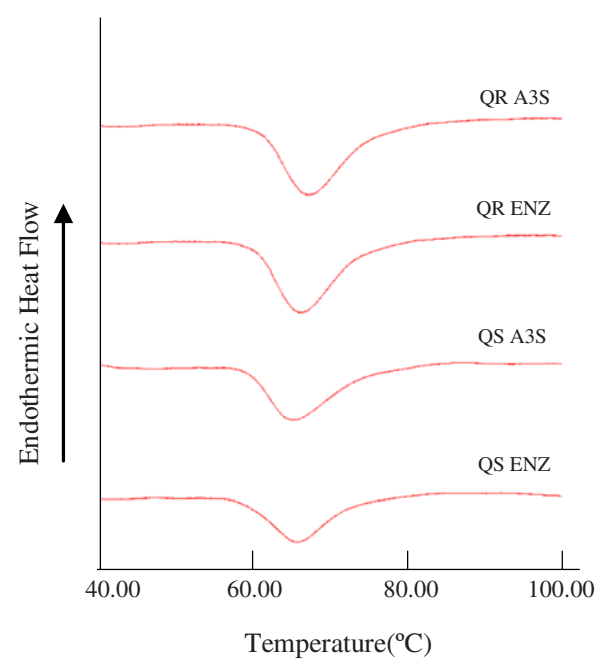

Fig. 3. Endothermic transitions of acorn starches. QR: Q. rotundifolia; QS: Q. suber; A3S: alkaline isolation method; ENZ: enzymatic isolation method. 
Table 3

Thermal properties of acorns starches isolated by A3S and ENZ methods.

\begin{tabular}{|c|c|c|c|c|c|c|c|c|}
\hline Starch sample & Isolation method & $T_{o}\left({ }^{\circ} \mathrm{C}\right)$ & $T_{p}\left({ }^{\circ} \mathrm{C}\right)$ & $T_{c}\left({ }^{\circ} \mathrm{C}\right)$ & $\Delta H(\mathrm{~J} / \mathrm{g})$ & $E_{a}\left(\mathrm{~J} \mathrm{~mol}^{-1}\right)$ & $T_{r}\left({ }^{\circ} \mathrm{C}\right)$ & PHI $\left.\left(\mathrm{J} / \mathrm{g}{ }^{\circ} \mathrm{C}\right)\right)$ \\
\hline \multirow[t]{2}{*}{ QR } & A3S & $60.9 \pm 0.0 \mathrm{a}$ & $66.7 \pm 0.0 a$ & $74.7 \pm 0.2 b$ & $4.2 \pm 0.1 \mathrm{a}$ & $2157 \pm 40 a$ & $11.6 \pm 0.4 a$ & $0.72 \pm 0.0 b$ \\
\hline & ENZ & $58.7 \pm 0.2 b$ & $65.7 \pm 0.1 b$ & $74.0 \pm 0.1 b c$ & $4.3 \pm 0.1 \mathrm{a}$ & $1874 \pm 44 b$ & $14.0 \pm 0.2 c$ & $0.61 \pm 0.05 a$ \\
\hline \multirow[t]{2}{*}{ QS } & A3S & $58.4 \pm 0.2 b$ & $64.8 \pm 0.1 c$ & $73.3 \pm 0.4 a$ & $4.2 \pm 0.1 \mathrm{a}$ & $2189 \pm 49 a$ & $12.4 \pm 0.6 a b$ & $0.68 \pm 0.03 a b$ \\
\hline & ENZ & $58.6 \pm 0.1 b$ & $64.1 \pm 0.1 c$ & $71.7 \pm 0.1 c$ & $4.3 \pm 0.1 a$ & $1875 \pm 58 b$ & $11.0 \pm 0.7 a$ & $0.78 \pm 0.02 c$ \\
\hline
\end{tabular}

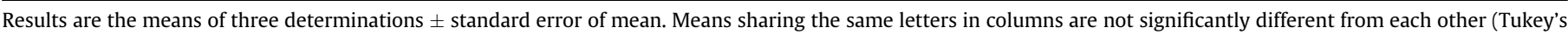
HSD test, $p<0.05$ ).

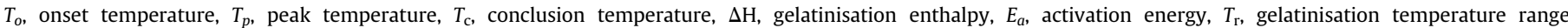

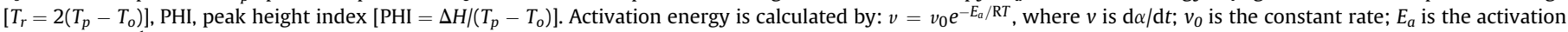
energy $\left(\mathrm{J} \mathrm{mol}^{-1}\right)$; $\mathrm{R}$ is the gas constant; and $T$ is the absolute temperature. A3S: alkaline starch isolation method; ENZ: enzymatic isolation method.

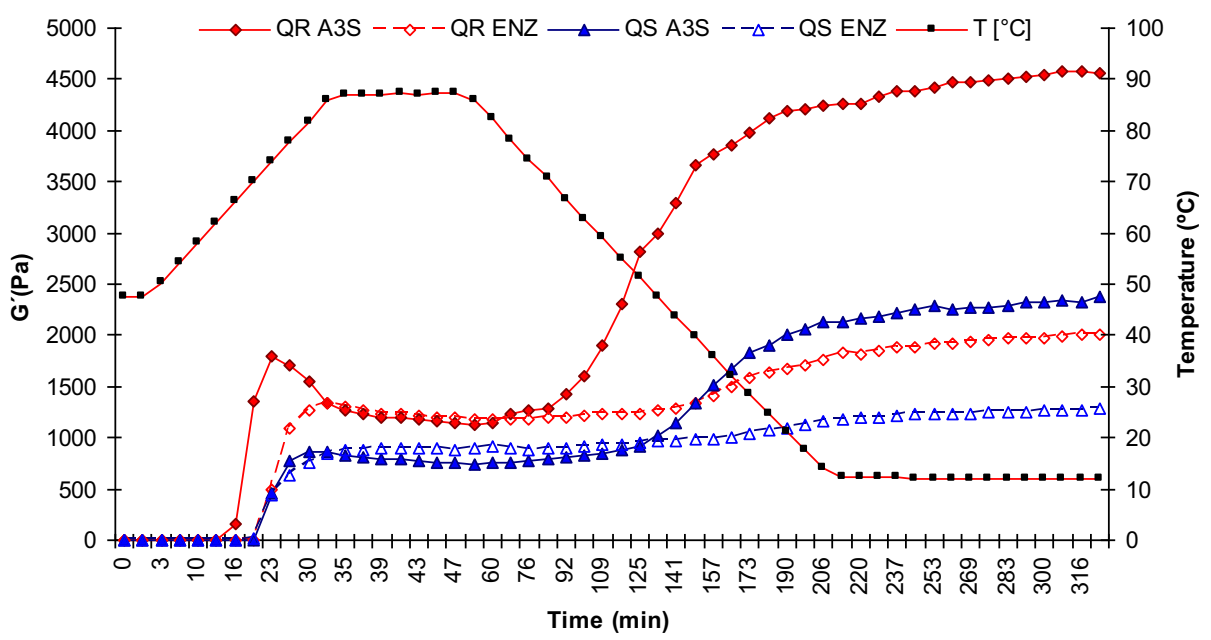

Fig. 4. valuation of $G^{\prime}$ of $10 \%$ starch suspensions of acorns. QR: Q. rotundifolia; QS: Q. suber; A3S: alkaline isolation method; ENZ: enzymatic isolation method.

(Stevenson et al., 2006), meaning a low degree of internal molecular organisation of the granules. A strong carbohydrate/water interaction and better organized microstructure lead to a higher $\Delta \mathrm{H}$ value (Chung, Lee, \& Lim, 2002), since $\Delta H$ indicates the required energy for disruption hydrogen bonds within the crystalline zones. It was also found significant differences were also found in activation energy.

The isolation method did not systematically affect the $T_{r}$ (gelatinisation temperature range) and PHI (peak height index) parameters on acorn starches. However, the high $T_{r}$ was found for QR ENZ starch suggests the presence of crystallites of varying stability within the crystalline domains of the granule (Singh, Kaur, Sandhu, \& Guraya, 2004), meaning that a large gap between onset and endset temperatures is probably due to a high heterogeneity of the crystallites present on starch granules. Furthermore, QR ENZ starch also presented a lower PHI, which could be related to a lower structured starch matrix, since this parameter provides a numerical value that is indicative of the relative shape of the endotherm. A tall narrow endotherm has a higher PHI than a shorter one, does even if the energy involved in the transition is the same (Krueger et al., 1987). Compare to QR starch behaviours, QS starches reacted in an opposite way, meaning that starch extracted by alkaline method presented the high $T_{r}$ and low PHI values.

The isolation starch method that seems to preserve in a higher degree the molecular order is the A3S method, which generally presented high transition temperatures.

\subsection{Rheological properties}

The rheological properties of starches isolated from different acorns flours are illustrated in Figs. 4 and 5, and Table 4. The storage modulus $\left(G^{\prime}\right)$ and loss modulus $\left(G^{\prime \prime}\right)$ were relatively low before the onset temperature of storage modulus $\left(\mathrm{T}_{\mathrm{oG}}\right)$, then increased during heating until rise to a maximum $\left(G^{\prime}{ }_{\max }\right.$ and $\left.G^{\prime \prime}{ }_{\max }\right)$ and then dropped during the continuous heating. A positive correlation was found between $G^{\prime}$ and $G^{\prime \prime}$ modulus $(r=0.963, p<0.01)$. Heating caused the swelling of starch granules, which always increase with temperature (Fig. 1) resulting in a $G^{\prime}$ increase to a maximum value (Singh et al., 2008). In all samples the $G^{\prime}$ was always higher than $G^{\prime \prime}$, meaning that the formed pastes were more elastic than viscous. The QR starches showed the highest $G^{\prime}, G^{\prime \prime}$ and breakdown values (Table 4). However, the $G^{\prime} / G^{\prime \prime}$ ratios are similar for all starches.

Except for the breakdown, the dynamic moduli reflect roughly the pasting properties of Table 2 , albeit that the dynamic moduli are much more sensitive to changes in physical structure than

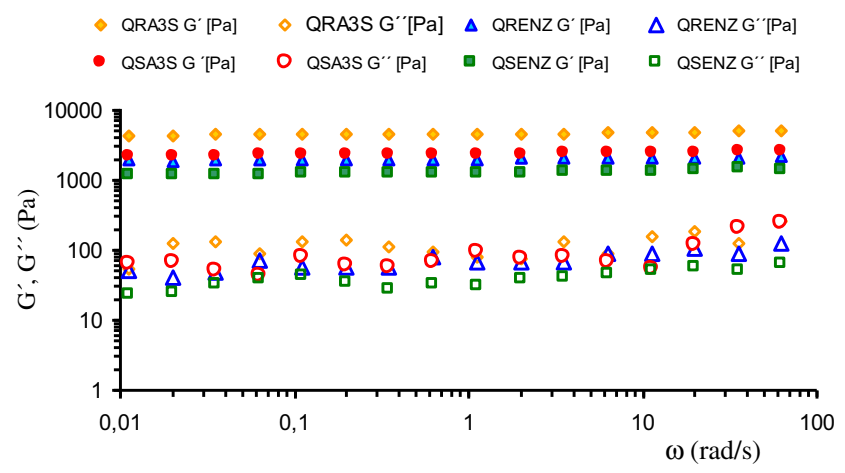

Fig. 5. Mechanical spectra at $10^{\circ} \mathrm{C}$ of acorn starches. QR: Q. rotundifolia; QS: Q. suber; A3S: alkaline isolation method; ENZ: enzymatic isolation method. 
Table 4

The rheological properties of acorn starches isolated by A3S and ENZ isolation methods.

\begin{tabular}{|c|c|c|c|c|c|c|c|c|}
\hline Sample & & $T_{o G^{\prime}}\left({ }^{\circ} \mathrm{C}\right)$ & $T_{G_{\max }^{\prime}}\left({ }^{\circ} \mathrm{C}\right)$ & $G_{\text {max }}^{\prime}(\mathrm{Pa})$ & $G^{\prime \prime} \max (\mathrm{Pa})$ & $G_{\text {max }}^{\prime \prime} / G_{\text {max }}^{\prime}$ & $\mathrm{BD}_{\mathrm{G}^{\prime}}(\mathrm{Pa})$ & $\tan \delta_{G_{\max }^{\prime}}$ \\
\hline Q. rotundifolia & A3S & $66.9 \pm 1.7 \mathrm{ab}$ & $83.1 \pm 0.6 a$ & $1795 \pm 68 a$ & $196.6 \pm 3.3 a$ & $0.11 \mathrm{a}$ & $666 \pm 42 a$ & $0.082 \pm 0.003 a$ \\
\hline & ENZ & $59.4 \pm 0.8 c$ & $72.4 \pm 0.2 b$ & $1493 \pm 127 a b$ & $131.3 \pm 3.0 b$ & $0.09 a$ & $305 \pm 29 b$ & $0.080 \pm 0.006 a b$ \\
\hline Q. suber & $\begin{array}{l}\text { A3S } \\
\text { ENZ }\end{array}$ & $\begin{array}{l}68.3 \pm 0.6 \mathrm{a} \\
65.7 \pm 1.1 \mathrm{ab}\end{array}$ & $\begin{array}{l}84.8 \pm 1.0 \mathrm{a} \\
*\end{array}$ & ${ }_{*}^{833 \pm 19 c}$ & ${ }_{*} 67.7 \pm 2.4 \mathrm{~d}$ & $0.08 \mathrm{a}$ & ${ }_{*}^{87} \pm 12 \mathrm{~d}$ & $\begin{array}{l}0.078 \pm 0.008 b \\
*\end{array}$ \\
\hline
\end{tabular}

*No maximum peak.

Results are the means of three determinations \pm standard error of mean.

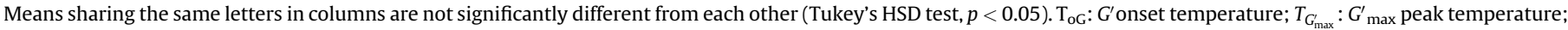

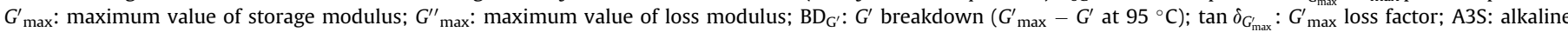
isolation method; ENZ: enzymatic isolation method.

Brabender viscosity. QS starches presented lower $G^{\prime}$ and $G^{\prime \prime}$ than QR starches. Generally, such behaviour is ascribed to differences in swelling behaviour (Eliasson, 1986; Keetels \& Van Vliet, 1994), but in the present case the swelling profiles were affected rather by starch isolation method than by starch type (Fig. 1). It is not improbable that differences in granule structure between the starches, notably the higher amylose content of QS starch (Table 1) play a role here. After attaining a maximum $G^{\prime}$ the decrease in $G^{\prime}$, possibly due to the disentanglement of amylopectin in the swollen particles (Wang et al., 2010), was more evident in QR starches. Lindqvist (1979) mentioned that both amylose and amylopectin play important roles in starch gelation. Amylose is reported to assist in maintaining granule integrity during heating (Morrison, Tester, Snape, Law, \& Gidley, 1993). This suggests that the lower breakdown of QS starch is explained by its higher amylose content (Table 1). The trend of peak $G^{\prime}$ temperatures for the various starches was similar to the transition temperatures measured by DSC (Table 3). However, the peak $G^{\prime}$ temperatures were consistently higher than their corresponding $T_{p}$, as was also reported by other authors (Singh et al., 2007). The insoluble granular fragments have a tendency to reassociate after heating, resulting in the formation of crystalline aggregates and a gelled texture (Thomas \& Atwell, 1999). This explains the increase in modulus (setback). Fig. 4 shows clearly that this setback is very pronounced for starches isolated by the alkali method (A3S), especially for QR A3S starch, but much less so for starches isolated by the enzyme method. The latter are fairly stable to cooling. The cooling behaviour of acorn starches and the strong effect of starch isolation method are difficult to explain and merit further investigation. Hot as well as cooled acorn starches presented $\tan \delta<0.1$ (Table 4, Fig. 5), which suggests that cooled acorn starches form a firm, self-supporting true gel (Sang, Bean, Seib, Pedersen, \& Shi, 2008). A very interesting result is that the $G^{\prime}$ modulus of all starches remains rather stable on storage at $10^{\circ} \mathrm{C}$, at least for several hours (Fig. 4). This stability appears to be fairly independent on the setback during cooling to $10{ }^{\circ} \mathrm{C}$. Mechanical spectra of the acorn starch gels after $2 \mathrm{~h}$ storage at $10^{\circ} \mathrm{C}$ are shown in Fig. 5. All starch gels had $G^{\prime}>G^{\prime \prime}$ and displayed a rather flat frequency dependence. This indicates that these systems behaved as true gels with limited molecular rearrangements occurring on a time scale of $0.01-100 \mathrm{~s}$. These results confirmed that $G^{\prime}$ and $G^{\prime \prime}$ of A3S starches were consistently higher than those of the ENZ starches, which suggests a higher degree of structuring in the A3S starch gels in comparison to the ENZ starch gels.

\section{Conclusions}

The application of starch from different origins in food systems depends greatly on chemical and functional properties of such food materials. Acorn starches presented high-amylose content, limited swelling power combined with low solubility and low gelatinisation temperatures. The isolation starch method that seems to preserve the molecular order to a higher degree, and consequently the functional properties of starches is the alkali method. The isolation method seems to affect $Q$. suber starches to a high degree.

The physicochemical and functional properties of acorn starches, a non-conventional source, suggest that these products may be used as an ingredient for foods and other industrial applications. The thermal transitions occur in a similar way in starches from both acorn species. Acorn starches presented high paste consistencies, with higher final and setback consistencies, and did not present a breakdown. Thus, QR and QS starches could be classified as to be tolerant to heating and shearing processes. The high consistency immediately acquired, when the acorn pastes were cooling, the high stability and strong formation of gels, and the low values of turbidity, suggest the possibility for new applications of this starch. Moreover, the observed high firmness and stability of the gel are adequate to be used as thickening, stabilising and jellifying agent in foods, but acorn starch is not adequate when it is included in frozen foods due to high syneresis effect.

The encountered results may credit acorn starches as a source for new forms of starch for special purposes. Since large quantities of acorns are produced each year, and left to rot, it is very important to convert this biomass into a potential source of carbohydrates for industrial uses.

\section{Acknowledgements}

The first author acknowledges financial support SFRH/BD/ 37755/2007 from Fundação para a Ciência e Tecnologia, Portugal.

\section{References}

Adebowale, K. O., Afolabi, T. A., \& Olu-Owolabi, B. I. (2006). Functional, physicochemical and retrogradation properties of sword bean (Canavalia gladiata) acetylated and oxidized starches. Carbohydrate Polymers, 65, 93-101.

Aee, L. H., Hie, K. N., \& Nishinari, K. (1998). DSC and rheological studies of the effects of sucrose on the gelatinization of acorn starch. Thermochimica Acta, 322, 39-46.

Ahmad, F. B., Williams, P. A., Doublier, J.-L., Durand, S., \& Buléon, A. (1999). Physico-chemical characteristics of sago starch. Carbohydrate Polymers, 38 361-370.

Barminas, J. T., Onen, A. I., Williams, E. T., Zaruwa, M. Z., Mamuru, S. A., \& Haggai, D. (2008). Studies on functional properties of borassus starch from fresh germinating nuts of giginya (Borassus aethiopum) palm. Food Hydrocolloids, 22, 298-304.

Chaisawang, M., \& Suphantharika, M. (2006). Pasting and rheological properties of native and anionic tapioca starches as modified by guar gum and xanthan gums. Food Hydrocolloids, 20, 641-649.

Charles, A. L. (2004). Some physical and chemical properties of starch isolates of cassava genotypes. Starch/Stärke, 56, 413-418.

Chung, H. J., Lee, E. J., \& Lim, S. T. (2002). Comparison in glass transition and enthalpy relaxation between native and gelatinized rice starches. Carbohydrate Polymers, 48, 287-298.

Correia, P. R., \& Beirão-da-Costa, M. L. (2010). Chestnut and acorn starch properties affected by isolation methods. Starch/Stärke, 62, 421-428.

Correia, P. R., \& Beirão-da-Costa, M. L. (2012). Isolation of starch from chestnut and acorn flours through alkali and enzymatic methods. Food and Bioproducts Processing, 90, 309-316.

Correia, P., Leitão, A., \& Beirão-da-Costa, M. L. (2009). Effect of drying temperatures on chemical and morphological properties of dried acorns flours. International Journal of Food Science and Technology, 44, 1729-1736. 
Correia, P. R., Nunes, M. C., \& Beirão-da-Costa, M. L. (2012). The effect of starch isolation method on physical and functional properties of Portuguese nuts starches. I. Chestnuts (Castanea sativa Mill. var. Martainha and Longal) fruits. Food Hydrocolloids, 27, 256-263.

Danielenko, A. N., Grozav, E. K., Rogova, E. I., Bikbov, T. M., Gringberg, V. Y., \& Tolstogusov, V. B. (1985). Studies on the stability of $11 \mathrm{~S}$ globulin from soybeans by differential scanning microcalorimetry. International Journal of Biological Macromolecules, 7, 109-112.

Eliasson, A. C. (1986). Viscoelastic behaviour during the gelatinization of starch. I. Comparison of wheat, maize potato, and waxy-barley starches. Journal of Texture Studies, 17, 253-265.

Ferrero, C., Martin, M. N., \& Zaritzky, N. (1994). Corn-starch-xanthan gum interaction and its effect on the stability during storage of frozen gelatinized suspentions. Starch/Stärke, 46, 300-305.

Hadimani, N. A., \& Malleshi, N. G. (1993). Studies on milling, physicochemical properties, nutrient composition and dietery fibre content of millet. Journal of Food Science and Technology, 30, 17-20.

Hoover, R., Hughes, T., Chung, H. J., \& Liu, Q. (2010). Composition, molecular structure, properties, and modifications of pulse starches: a review. Food Research International, 43, 399-413.

Juliano, B. O. (1971). A simplified assay for milled-rice amylose. Cereal Science Today, $16,334-340$.

Kaur, L., Singh, J., \& Singh, N. (2006). Effects of cross-linking on some properties of potato starches. Journal of the Science of Food and Agriculture, 86, 1945-1954.

Kaur, L., Singh, N., \& Sodhi, N. S. (2002). Some properties of potatoes and their starches II. Morphological, thermal and rheological properties of starches. Food Chemistry, 79, 183-192.

Keetels, C. J. A. M., \& Van Vliet, T. (1994). Gelation and retrogradation of concentrated starch gels. In G. O. Philips, P. A. Williams, \& D. J. Wedlock (Eds.), Gum and stabilisers for the food industry (pp. 271-280). Oxford: IRL Press.

Krueger, B. R., Knutson, C. A., Inglett, G. E., \& Walker, C. E. (1987). A differential scanning calorimetry study on the effect of annealing on gelatinization behaviour of corn starch. Journal of Food Science, 52, 715-718.

Lan, W., Zhihua, Y., Yun, Z., Bijun, X., \& Zhida, S. (2008). Morphological, physicochemical and textural properties of starch separated from Chinese water chestnut. Starch/Starke, 60, 181-191.

Lindqvist, I. (1979). Cold gelation on starch. Starch/Stärke, 31, 195-200.

Liu, Q. (2005). Understanding starches and their role in food. In S. Cui (Ed.), Food carbohydrates: Chemistry, physical properties, and applications (pp. 309-349). New York: CRC Press Taylor \& Francis Group.

McCleary, B. V., Charnock, S. J., Rossiter, P. C., O’Shea, M., Power, A. M., \& Lloyd, R. M. (2006). Measurement of carbohydrates in grain, feed and food. Journal of the Science of Food and Agriculture, 86, 1648-1661.

Mirmoghtadaie, L., Kadivar, M., \& Shahedi, M. (2009). Effects of cross-linking and acetylation on oat starch properties. Food Chemistry, 116, 709-713.

Morrison, W. R., Tester, R. F., Snape, C. E., Law, R. V., \& Gidley, M. J. (1993). Swelling and gelatinization of cereal starches. IV. Some effect on lipids complexed amylose an free amylose in waxy and normal barley starches. Cereal Chemistry, 70, 385-391.
Mun, S., \& Shin, M. (2006). Mild hydrolysis of resistant starch from maize. Food Chemistry, 96, 115-121.

Naguleswaran, S., Vasathan, T., Hoover, R., \& Liu, Q. (2010). Structure and physicochemical properties of palmyrah (Borassus flabellifer L.) seed-shoot starch grown in Sri Lanka. Food Chemistry, 118, 634-649.

Otebayo, B., Aina, J., Asiedu, R., \& Bokanga, M. (2006). Pasting characteristics of fresh yams (Dioscorea spp.) as indicators of textural quality in a major food product-“pounded yam". Food Chemistry, 99, 663-669.

Perera, C., \& Hoover, R. (1999). Influence of hydroxypropylation on retrogradation properties of native, defatted and heat-moisture treated potato starches. Food Chemistry, 64, 361-375.

Rakic, S., Povrenovic, D., Tesevic, V., Simic, M., \& Maletic, R. (2006). Oak acorn, polyphenols and antioxidant activity in functional food. Journal of Food Engineering, 74, 416-423.

Ribeiro, O. (1992). Formação de Portugal. Lisboa: Instituto de Cultura e Língua Portuguesa (ICALP)

Rondán-Sanabria, G. G., \& Finardi-Filho, F. (2009). Physical-chemical and functional properties of maca root starch (Lepidium meyenii Walpers). Food Chemistry, 114, 492-498.

Sang, Y., Bean, S., Seib, P. A., Pedersen, J., \& Shi, Y.-C. (2008). Structure and functional properties of sorghum starches differing in amylose content. Journal of Agricultural and Food Chemistry, 56, 6680-6685.

Singh, G. D., Bawa, A. S., Singh, S., \& Saxena, D. C. (2009). Physicochemical, pasting thermal and morphological characteristics of Indian water chestnut (Trapa natans) starch. Starch/Stärke, 61, 35-42.

Singh, J., \& Singh, N. (2001). Studies on morphological, thermal and rheological properties of starches separated from some Indian potato cultivars. Food Chemistry, 75, 67-77.

Singh, N., Nakaura, Y., Inouchi, N., \& Nishinari, K. (2008). Structure and viscoelastic properties of starches separated from different legumes. Starch/Stärke, 60, 349-357.

Singh, N., Nakaura, Y., Inouchi, N., \& Nishinari, K. (2007). Fine structure, thermal and viscoelastic properties of starches separated from Indica rice cultivars. Starch/ Stärke, 59, 10-20.

Singh, N., Kaur, M., Sandhu, K. S., \& Guraya, H. S. (2004). Physico-chemical, thermal, morphological and pasting properties of starches from some Indian black gram (Phaseolus mungo L.) varieties. Starch/Stärke, 56, 535-544.

Soni, P. L., Sharma, Dun, D., \& Gharia, M. M. (1993). Physicochemical properties of Quercus leucotrichophora (oak) starch. Starch/Stärke, 45, 127-130.

Stevenson, D. G., Jane, J.-L., \& Inglett, G. E. (2006). Physicochemical properties of pin oak (Quercus palustris Muench.) acorn starch. Starch/Stärke, 58, 553-560.

Themeier, H., Hollmann, J., Neese, U., \& Linndhauer, M. G. (2005). Structural and morphological factors influencing the quantification of resistant starch II in starches of different botanical origin. Carbohydrate Polymers, 61, 72-79.

Thomas, D. J., \& Atwell, W. (1999). Starches. St. Paul, Minnesota. USA: Eagan Press.

Wang, L., Xie, B., Shi, J., Xue, S., Deng, Q., Wei, Y., et al. (2010). Physicochemical properties and structure of starches from Chinese rice cultivars. Food Hydrocolloids, 24, 208-216. 